\title{
Ultrasensitive haptoglobin biomarker detection based on amplified chemiluminescence of magnetite nanoparticles
}

\author{
Narsingh R. Nirala' ${ }^{1}$, Yifat Harel ${ }^{2}$, Jean-Paul Lellouche ${ }^{2}$ and Giorgi Shtenberg ${ }^{1 *}$ (1)
}

\begin{abstract}
Background: Haptoglobin is an acute-phase protein used as predicting diagnostic biomarker both in humans (i.e., diabetes, ovarian cancer, some neurological and cardiovascular disorders) and in animals (e.g., bovine mastitis). The latter is a frequent disease of dairy industry with staggering economical losses upon decreased milk production and increased health care costs. Early stage diagnosis of the associated diseases or inflammation onset is almost impossible by conventional analytical manners.

Results: The present study demonstrates a simple, rapid, and cost-effective label-free chemiluminescence bioassay based on magnetite nanoparticles (MNPs) for sensitive detection of haptoglobin by employing the specific interaction of hemoglobin-modified MNPs. The resulting haptoglobin-hemoglobin complex inhibits the peroxidase-like activity of luminol/ $\mathrm{H}_{2} \mathrm{O}_{2}$-hemoglobin-MNPs sensing scheme and reduces the chemiluminescence intensities correspondingly to the innate haptoglobin concentrations. Quantitative detection of bovine haptoglobin was obtained within the range of $1 \mathrm{pg} \mathrm{mL}^{-1}$ to $1 \mathrm{\mu g} \mathrm{mL}^{-1}$, while presenting $0.89 \mathrm{pg} \mathrm{mL}^{-1}$ limit of detection. Moreover, the influence of causative pathogenic bacteria (i.e., Streptococcus dysgalactiae and Escherichia coli) and somatic cell counts (depicting healthy, sub-clinical and clinical mastitis) on the emitted chemiluminescence radiation were established. The presented bioassay quantitative performances correspond with a standardized assay kit in differentiating dissimilar milk qualities.
\end{abstract}

Conclusions: Overall, the main advantage of the presented sensing concept is the ability to detect haptoglobin, at clinically relevant concentrations within real milk samples for early bio-diagnostic detection of mastitis and hence adjusting the precise treatment, potentially initiating a positive influence on animals' individual health and hence on dairy farms economy.

Keywords: Chemiluminescence, Haptoglobin, Magnetic iron oxide nanoparticles, Mastitis, Pathogens

\section{Background}

Acute-phase proteins (APP) are prevalent predicting indicators (biomarkers) for diagnostic health status estimation both in humans and animals, utilizing their distribution alteration in plasma due to infection,

*Correspondence: giorgi@agri.gov.il

${ }^{1}$ Institute of Agricultural Engineering, ARO, The Volcani Center, 50250 Bet Dagan, Israel

Full list of author information is available at the end of the article inflammation or trauma [1-6]. The acute-phase response of homeostasis disturbance produces a cascade of mRNA upregulation which results in some blood proteins augmentation, while decreasing the synthesis of others [7]. A valid example of this response is the hepatically derived APP, e.g., C-reactive protein, serum amyloid A and haptoglobin $(\mathrm{Hp})$, which are released by the hepatocytes cascade due to cytokine stimulation [5, 8-11]. The latter is a widely used APP biomarker both in humans (i.e., diabetes, ovarian cancer, some neurological and cardiovascular

c) The Author(s) 2020. This article is licensed under a Creative Commons Attribution 4.0 International License, which permits use, sharing, adaptation, distribution and reproduction in any medium or format, as long as you give appropriate credit to the original author(s) and the source, provide a link to the Creative Commons licence, and indicate if changes were made. The images or other third party material in this article are included in the article's Creative Commons licence, unless indicated otherwise in a credit line to the material. If material is not included in the article's Creative Commons licence and your intended use is not permitted by statutory regulation or exceeds the permitted use, you will need to obtain permission directly from the copyright holder. To view a copy of this licence, visit http://creativeco mmons.org/licenses/by/4.0/. The Creative Commons Public Domain Dedication waiver (http://creativecommons.org/publicdomain/ zero/1.0/) applies to the data made available in this article, unless otherwise stated in a credit line to the data. 
disorders) and in animals (e.g., bovine mastitis), increasing its concentration in plasma up to 100-folds [10]. Hp is widely applied for health status evaluation of dairy cows suffering from bovine mastitis, a recurrent disease of the dairy industry that causes substantial economical loses considering increased health care costs and decreased milk production $[1,5,6]$. Hp is usually secreted by permeable mammary vascular cells, thus augmenting its concentration in milk [12]. The mammary gland inflammation is classified as sub-clinical, clinical, and chronic forms, and is dependent on the causative pathogen origin, animal's lactation state and immune health [10]. Conventionally, bovine mastitis detection depends on the efficiency of the methods designed to estimate somatic cell counts (SCC), indicate inflammation, identify the causative microorganisms or quantify the biomarkers associated with the disease [6]. Milk and plasma Hp distributions are commonly detected by conventional immunoassays based on hemoglobin $(\mathrm{Hb})$ binding affinity, which are expensive and time-consuming $[2,6]$.

Chemiluminescence (CL) is a practical opto-chemical approach for designing real-life sensing applications, e.g., safety control within food and pharmaceutical industries, environmental hazardous contaminants monitoring and clinical examination, using the discharged radiation for high sensitivity analysis of the target molecule [13-18]. The addition of superparamagnetism characteristics onto CL bioassays in means of magnetic nanoparticles (MNPs), alleviate the high-throughput immunoassay protocols by convenient separation, widespread the linear sensing range, enhance the reaction kinetics and encompass high surface area for collected biomolecular recognition [19]. Indeed, ample research reports employed MNPs within CL bioassays presenting a list of innovative ultrasensitive sensing schemes [2025]. Jie et al. have employed gold-coated MNPs for ultrasensitive targeting of fumonisin B1 in cereals and wheat based on CL immunoassay [22]. The developed assay presented a low detection limit of $27 \mathrm{pg} \mathrm{mL}^{-1}$ fumoni$\sin \mathrm{B} 1$ and a dynamic range of 0.05 to $25 \mathrm{ng} \mathrm{mL}^{-1}$. The high-throughput screening methodology overpowered conventional analytical performances and presented recoveries of $91-110 \%$ in real samples [22]. A similar sensing concept was used for zearalenone mycotoxin (produced by Fusarium species) ultrasensitive CL detection [26]. The authors reported a 50-fold pre-concentration of zearalenone in bulk vine samples and its detection as low as $4 \mathrm{pg} \mathrm{mL}^{-1}$, more than an order of magnitude increase in sensitivity with respect to colorimetric assay and to MNPs-enzyme-linked immunosorbent assay (ELISA) without pre-concentration procedure (detection limits of 0.06 and $0.1 \mathrm{ng} \mathrm{mL}^{-1}$, respectively). Zhang et al. have demonstrated sandwich-type CL immunoassay based on carboxyl-functionalized MNPs modified with anti- $\alpha$-humanchorionic gonadotropin (hCG) antibody [19]. Under optimized conditions, the assay was sensitive to $1.184 \mathrm{ng} \mathrm{mL}^{-1}$ analyte within the dynamic range of 2 to $100 \mathrm{ng} \mathrm{mL} \mathrm{m}^{-1}$. The proposed method could be easily adapted for hCG quantitative detection in serum samples by utilizing the potent advantages of the bioassay for clinical diagnosis (decrease in immune-reagents dosage, high-sensitivity, rapid and simplified protocol) [19].

Herein, we have designed and fabricated CL bioassay for ultrasensitive analysis of Hp content in bovine milk, by employing the specific interaction of $\mathrm{Hb}$-modified MNPs. The resulting $\mathrm{Hb}-\mathrm{Hp}$ complex formation inhibit the peroxidase-like activity of luminol/ $\mathrm{H}_{2} \mathrm{O}_{2}-\mathrm{Hb}$-MNPs system, thus offering means for analytical evaluation of Hp content, as schematically illustrated in Fig. $1[9,10]$. The correlation between CL signal and Hp concentration of dissimilar milk samples was effectively attained. Moreover, the impact of SCC levels and pathogen types, i.e., Streptococcus dysgalactiae and Escherichia coli (Strep. dysgalactiae and E. coli, respectively), on the secreted Hp was studied in comparison to healthy udder. Finally, the bioassay performances were compared with the sensing data of a commercial ELISA kit.

\section{Materials and methods \\ Materials}

Iron(III) chloride hexahydrate, iron(II) chloride tetrahydrate, ammonium hydroxide, analytical grade buffers, bovine $\mathrm{Hp}$, bovine $\mathrm{Hb}$, glutaric dialdehyde (50 wt\%), gelatin, $\mathrm{H}_{2} \mathrm{O}_{2}$, luminol sodium salt and sodium hydroxide were obtained from Sigma-Aldrich Chemicals. Hp ELISA Kit was supplied by Abcam (cat. num. ab137977). Milli-Q water $(18 \mathrm{M} \Omega \mathrm{cm})$ was used for all the denoted experiments.

\section{MNPs synthesis}

Iron(III) chloride hexahydrate $(240 \mathrm{mg}, 0.9 \mathrm{mmol})$ dissolved in deoxygenated milliQ purified $\mathrm{H}_{2} \mathrm{O}(4.5 \mathrm{~mL})$ was mixed with an aqueous solution of iron(II) chloride tetrahydrate $\left(97.5 \mathrm{mg}, 0.45 \mathrm{mmol}, 4.5 \mathrm{~mL} \mathrm{H}_{2} \mathrm{O}\right.$ ). This solution was kept under nitrogen atmosphere and ultra-sonicated (Bransonic $^{\circledR}$ ultrasonic cleaner bath, $2510 \mathrm{E}$ MTH model, $42 \mathrm{kHz}$ at full power) for 5-10 min at room temperature (RT). Then, a concentrated $24 \%$ weight ammonium hydroxide aqueous solution $(0.75 \mathrm{~mL})$ was introduced in one shot, resulting in immediate black precipitation of magnetite $\left(\mathrm{Fe}_{3} \mathrm{O}_{4}\right)$ nanoparticles (MNPs). Sonication was continued for 10 additional minutes. Resulting MNPs were magnetically decanted (using a strong external magnet) and washed 3 times with ultrapure water $(30 \mathrm{~mL})$ until neutrality. Then, brilliant black free flowing MNPs were stored for $2 \mathrm{~h}$ as a $30 \mathrm{~mL}$ 


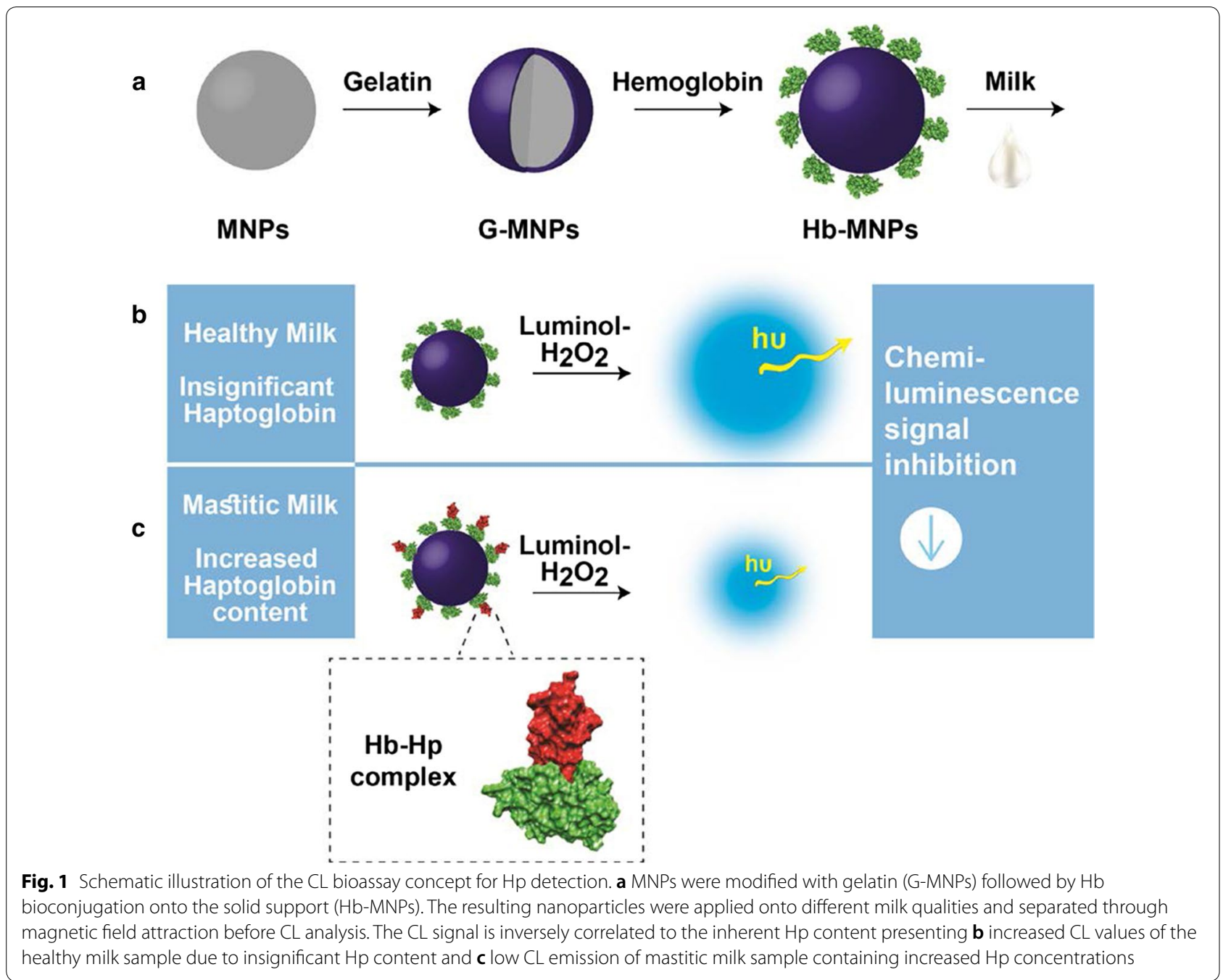

suspension in ultrapure water before any further processing (an aging process), washed once again and redispersed in $25 \mathrm{~mL}$ of ultrapure water.

\section{Instrumentation}

The absorption spectra and CL intensities were analyzed with Varioskan ${ }^{\mathrm{TM}}$ LUX (by Thermo Scientific, Waltham, MA, USA), a multimode microplate reader [9]. The structural morphology and size distribution of the different nanoparticles were studied by transmission electron microscopy (TEM), JEOL JEM-1400, operated at $120 \mathrm{kV}$. Dynamic light scattering (DLS) was used to analyze the hydrodynamic diameter of the functionalized MNPs using a Zetasizer Nano ZS (Malvern Instruments Ltd., Malvern, UK) while performing the measurements at RT [9]. The results were obtained from number-based distributions. Attenuated total reflectance Fourier transform infrared (ATR-FTIR) spectroscopy was used to further confirm MNPs surface modification using Thermo
Scientific Nicolet iS50, as previously noted [27]. Image analysis was performed by ImageJ software.

\section{Milk samples collection and preparation}

Milk samples were obtained from specific quarters of Holstein cows (Volcani Center) depicting healthy, spontaneous sub-clinical or clinical mastitis, as previously described [10]. All milk samples prior optical examination were defatted by mild centrifugal force of $2000 \times g$ for 10 min and tenfold diluted [10].

\section{MNPs biofunctionalization}

MNPs biofunctionalization was performed following a reported protocol by Nirala et al. (Fig. 1a) [10]. Briefly, $200 \mu \mathrm{L}$ gelatin aqueous $(1 \% \mathrm{wt} / \mathrm{v})$ solution were added onto $1 \mathrm{~mL}$ of diluted MNPs $\left(0.49 \mathrm{mg} \mathrm{mL}^{-1}\right)$ and allowed to react for $1 \mathrm{~h}$ at RT during mild orbital shaking (750 rpm). The resulting solution was thoroughly cleaned with ultrapure water $(1 \mathrm{~mL})$ by collecting the modified 
nanoparticles with a homemade magnetic separation unit (using two neodymium cubes $15 \times 15 \times 15 \mathrm{~mm}$, N35, Ni$\mathrm{Cu}-\mathrm{Ni}$ coating, $8.5 \mathrm{~kg}$ holding force each) for $5 \mathrm{~min}$ and redispersing the content to a final volume $1 \mathrm{~mL}$ (repeated three times) resulting in gelatin functionalized MNPs (G-MNPs). Next, G-MNPs were incubated with $200 \mu \mathrm{L}$ of $2.5 \mathrm{wt} \%$ glutaraldehyde solution for $0.5 \mathrm{~h}$ at RT to activate functional binding residues followed by repeating washing procedure to a final volume of $1 \mathrm{~mL}$. Finally, 200 $\mu \mathrm{L}$ of $\mathrm{Hb}$ solution $\left(1,10\right.$ and $\left.100 \mu \mathrm{g} \mathrm{mL}^{-1}\right)$ in ultrapure water was allowed to crosslink for $1 \mathrm{~h}$ at RT, proceeded by a post-cleaning procedure to a final volume of $0.5 \mathrm{~mL}$, resulting in Hb-modified MNPs (Hb-MNPs). The immobilized $\mathrm{Hb}$ content was analyzed indirectly by quantifying the residual washing solution content by Bradford dyebinding method [28].

\section{Bioassay calibration and $\mathrm{Hp}$ quantification in milk}

Reference bovine Hp solutions (different concentrations in the range of 0 to $1 \mu \mathrm{g} \mathrm{mL}^{-1}$ in PBS $\mathrm{pH}$ 7.4) were reacted with $\mathrm{Hb}-\mathrm{MNPs}$ for $30 \mathrm{~min}$ at RT during mild shaking (200 and $500 \mu \mathrm{L}$, respectively), followed by the above post-cleaning procedure to exclude any unbounded or interfering species. Next, $200 \mu \mathrm{L}$ of tenfold diluted healthy milk samples (containing insignificant Hp residues) were added onto the solution, allowed to react for $30 \mathrm{~min}$ at RT and cleaned similarly. The resulting solution $(100 \mu \mathrm{L})$ was calibrated by instantaneous CL examination following the addition of $100 \mu \mathrm{L}$ of alkaline luminol/ $/ \mathrm{H}_{2} \mathrm{O}_{2}$ solution (1.5 mM sodium hydroxide, $1 \mu \mathrm{M} \mathrm{H}_{2} \mathrm{O}_{2}, 45 \mu \mathrm{M}$ luminol sodium salt) while evaluating the emitted radiation values [10]. Milk samples were analyzed similarly, i.e., $200 \mu \mathrm{L}$ tenfold diluted of unknown samples were incubated for 30 min with Hb-MNPs at RT during mild shaking, followed by a post-cleaning in ultrapure water. CL studies of the dissimilar milk qualities were evaluated immediately by applying alkaline luminol $/ \mathrm{H}_{2} \mathrm{O}_{2}$ solution. The obtained emission values were used to calculate $\mathrm{Hp}$ concentrations based on the calibration curve and were paired to the values of bovine Hp ELISA kit [10].

\section{Statistical analysis}

T-test with a minimum confidence level of 0.05 was used for statistical significance (assuming unequal sample sizes and unequal variance). All values are reported as the mean $\pm \operatorname{SD}(\mathrm{n} \geq 3)$.

\section{Results and discussion}

\section{Optical and structural characterization} of biofunctionalized MNPs

The overall concept of the presented CL bioassay is to utilize the binding capacity and the catalytic activity of bovine Hb-modified carriers. Thus, $\mathrm{Hb}$ was applied on magnetic $\mathrm{Fe}_{3} \mathrm{O}_{4}$ nanoparticles through a standard biofunctionalization approach [10]. Briefly, MNPs were synthesized by using bath sonication method by mixing iron(III) chloride and iron(II) chloride solutions according to a previous work [29]. The obtained MNPs were subsequently decorated by gelatin molecules for attributing functional groups for cross-linking $\mathrm{Hb}$ on the exterior of the magnetic carriers and for minimizing the nonspecific adsorption of milk constituents during the bioassay protocol $[9,10]$. Next, the gelatin-free amino groups were modified with glutaraldehyde to activate the surface for $\mathrm{Hb}$ immobilization [30]. Note: assuming insignificant particles loses throughout the vigorous rinsing steps and biofunctionalization processes the concentration was set to $0.49 \mathrm{mg} / \mathrm{mL}$ of magnetite. The resulting MNPs surface modifications and morphologies were characterized by UV-VIS, ATR-FTIR and TEM, see Fig. 2. The absorbance spectra show a characteristic shoulder band edge that is red shifted, i.e., 363, 371, $396 \mathrm{~nm}$ for bare MNPs, G-MNPs, Hb-MNPs, respectively (Fig. 2a). The red shift is mainly ascribed to the nanoparticles collective diameter increase upon surface loading with gelatin and subsequently cross-linking with $\mathrm{Hb}$ creating cluster formation. MNPs surface characterization was further examined by ATR-FTIR studies, see Fig. 2b. The bare MNPs IR spectrum depicts intense characteristic $\mathrm{Fe}-\mathrm{O}$ stretching vibration peak at $532 \mathrm{~cm}^{-1}$ of bulk magnetite, absorption peak at $1634 \mathrm{~cm}^{-1}$ denoted to hydroxyl groups bending vibration, and a broad peak around $3347 \mathrm{~cm}^{-1}$ accredited to the stretching vibration of $-\mathrm{OH}$ residues in aqueous media [25]. Gelatin modification is characterized by the addition of two new peaks at 1636 and $1539 \mathrm{~cm}^{-1}$ corresponding to amide I and amide II of the protein, respectively, while the intensity of $\mathrm{Fe}-\mathrm{O}$ stretching vibration is decreased [20, 24]. Lastly, similar spectrum was obtained for $\mathrm{Hb}-\mathrm{MNPs}$, while further decrease in the $\mathrm{Fe}-\mathrm{O}$ peak intensity is shown while both amide I and amide II peaks intensities are respectively increased as additional protein residues are attached onto the G-MNPs surface. Overall, the additional absorption peaks of G-MNPs and $\mathrm{Hb}-\mathrm{MNPs}$ spectra suggest outer protein coverage. Additionally, Additional file 1: Table S1 presents the peak area ratio of both amide bonds $v s$ the peak area of $\mathrm{Fe}-\mathrm{O}$, which is increased upon surface modification. Finally, the fine structures of the different MNPs were elucidated by TEM, see Fig. 2c. Figure 2 (c1) shows representative bare MNPs which are relatively uniform in size and are within the range of $9.8 \pm 0.5 \mathrm{~nm}$ as individual nanoparticles and mini aggregates of $96 \pm 31 \mathrm{~nm}$ in size. The unmodified nanoparticles upon protein adsorption and cross-linking are size augmented and form greater clusters of $175 \pm 39$ and $310 \pm 121 \mathrm{~nm}$ for G-MNPs and Hb-MNPs, respectively, see Fig. 2 (c2) and (c3). Additional file 1: Table S2 

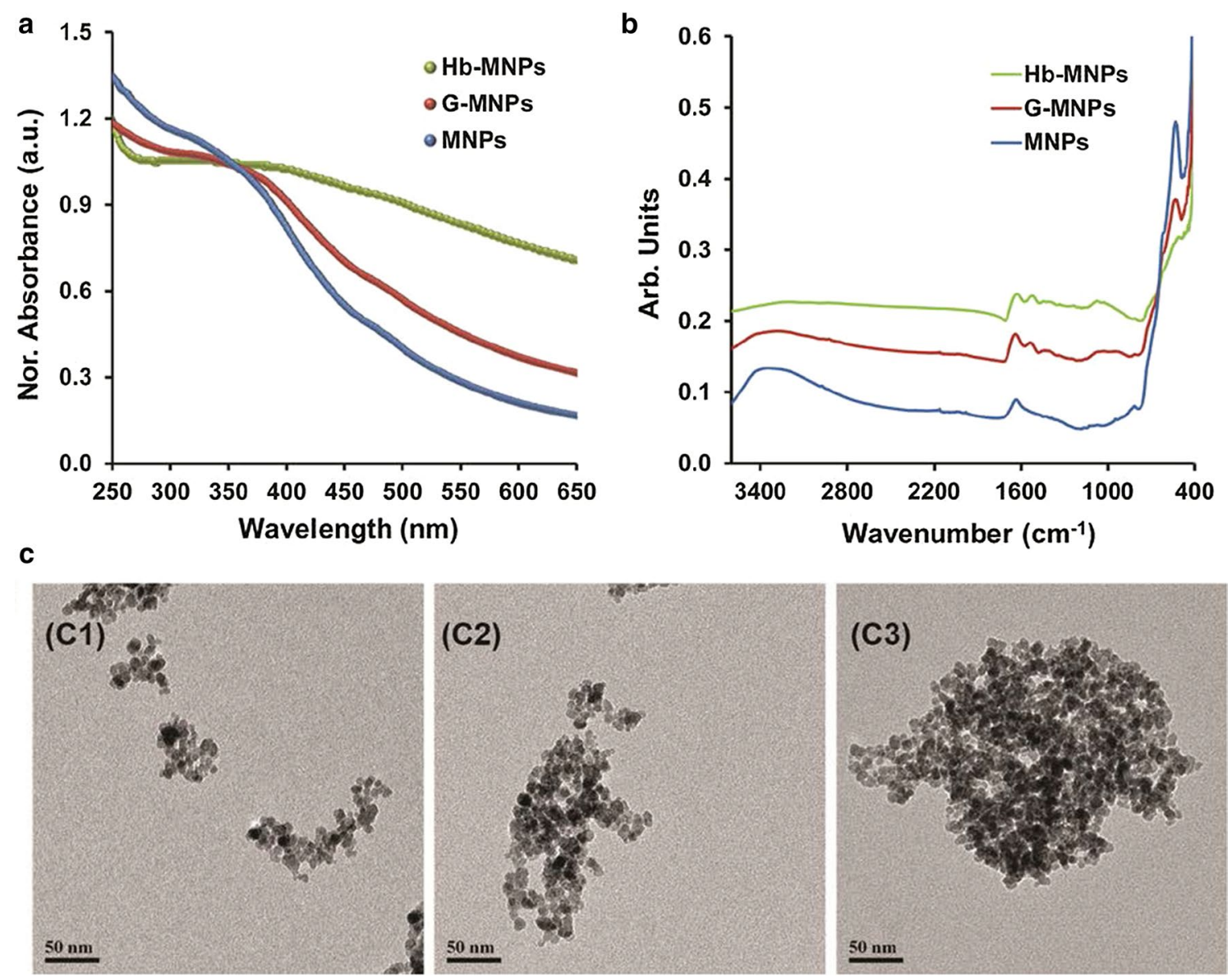

Fig. 2 a Normalized UV-VIS and $\mathbf{b}$ ATR-FTIR spectra of the modified MNPs: bare MNPs; G-MNPs and Hb-MNPs; c TEM images of the modified MNPs: (c1) bare MNPs, (c2) G-MNPs and (c3) Hb-MNPs presenting aggregates of $96 \pm 31,175 \pm 39$ and 310 \pm 121 , respectively. Data are reported as mean $\pm S D(n \geq 8)$ obtained by ImageJ software

depicts the collective hydrodynamic cluster dimensions acquired by DLS measurements. The obtained results are in agreement with UV-VIS and TEM studies indicating supercluster formation upon sequential surface modification $(211 \pm 6,469 \pm 31$ and $535 \pm 173 \mathrm{~nm}$ for bare MNPs, G-MNPs and Hb-MNPs, respectively). It should be noted that the DLS data overestimation with respect to TEM dimensions, is attributed to the different factors affecting intrinsic measurements, as previously shown [31-33].

\section{CL characterization of modified MNPs}

The peroxidase mimetic activity of $\mathrm{Hb}$ in luminol $/ \mathrm{H}_{2} \mathrm{O}_{2}$ $\mathrm{CL}$ system is well documented presenting the applicability of the sensing concept for ample analytical detection approaches [17, 34-38]. Therefore, the incorporation of a catalyst onto magnetic support via surface chemistry should eliminate any opto-chemical response that can be translated to intensified background luminescence. Meaning, the applied counterparts of the carrier system (gelatin, cross-linker and the magnetic carrier itself) should eliminate any false-positive emitted radiation, ensuring optically inert substances. Thus, the kinetic CL signal stability of the different MNPs modifications within the luminol system were investigated. Figure 3 depicts the obtained $C L$ values of unmodified and protein (i.e., gelatin and $\mathrm{Hb}$ )-decorated magnetic carriers. Indeed, extensively stable CL signals of Hb-MNPs at various potential concentrations of catalyst were perceived $\left(4122 \pm 71 \times 10^{3}, 1661 \pm 15 \times 10^{3}, 214 \pm 7 \times 10^{3}\right.$ a.u. for $100,10,1 \mu \mathrm{g} \mathrm{mL}{ }^{-1}$, respectively) under optimized experimental conditions [10]. It should be noted that although MNPs were functionalized with high content of $\mathrm{Hb}$ $(6.4 \pm 1.4,0.6 \pm 0.4 \mu \mathrm{g} \mathrm{Hb}$ per $0.49 \mathrm{mg}$ magnetite for 100 , $10 \mu \mathrm{g} \mathrm{mL}{ }^{-1}$, respectively, see Additional file 1: Table S3), the optical response retained its stability over the entire duration of the assay, thus presenting controlled consumption of the reaction constituents. In the absence of catalytically active biomolecules, the reactions of both bare MNPs and G-MNPs with luminol $/ \mathrm{H}_{2} \mathrm{O}_{2}$ system showed weak CL emission $\left(54 \pm 6 \times 10^{3}\right.$ and $15 \pm 6 \times 10^{3}$ 

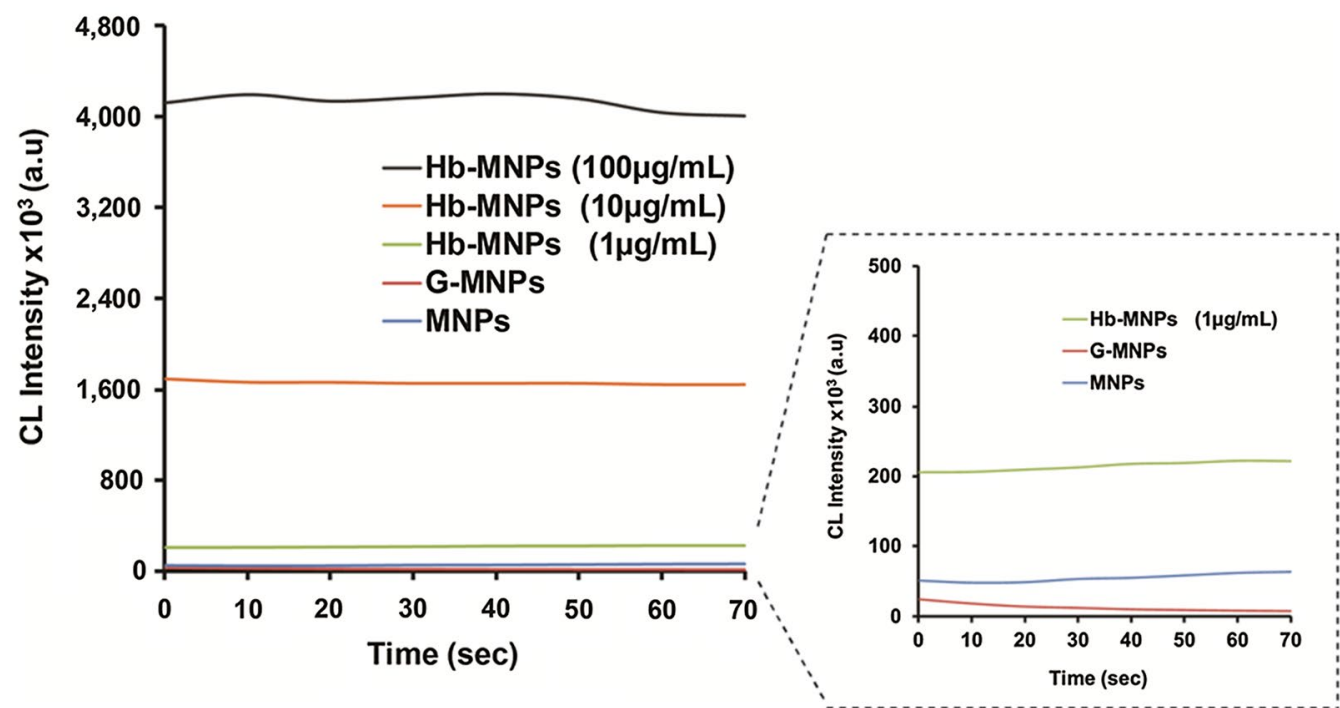

Fig. $3 \mathrm{CL}$ signal stability of the different MNPs modifications: bare MNPs; G-MNPs and Hb-MNPs, over time for the luminol system. The latter modification was assessed for three concentrations of catalyst: 1, 10, and $100 \mu \mathrm{g} \mathrm{mL} \mathrm{L}^{-1}$ of Hb. Inset: enlargement of the different MNPs modifications

a.u., respectively). Moreover, the different Hb concentrations on the exterior of MNPs carriers were examined within two dissimilar milk qualities (healthy and clinical mastitis) with respect to milk free conditions. Additional file 1: Figure S1 presents that the boundary conditions for quality estimation, low and high Hp concentrations, could be significantly differentiated by utilizing the highest catalyst content $\left(100 \mu \mathrm{g} \mathrm{mL}{ }^{-1}\right.$ of $\left.\mathrm{Hb}\right)$ for the noted bioassay. Considering the pronounced CL signal, stability over time and the ability to differentiate dissimilar milk qualities, our previously reported optimized conditions (alkaline luminol $/ \mathrm{H}_{2} \mathrm{O}_{2}$ solution) were adapted for the analytical evaluation of $\mathrm{Hp}$ within real milk samples [9, 10], while modifying the magnetic carrier with a substantial content of $\mathrm{Hb}\left(100 \mu \mathrm{g} \mathrm{mL}^{-1}\right)$.

\section{CL bioassay within milk samples}

The practical aspect and analytical determination of the developed bioassay for Hp detection within real samples was investigated for comprehensive biomarker content evaluation. Table 1 summarizes the analyzed milk samples acquired from various udders, which represent the entire milk quality spectrum. Three levels of SCC, approx. 300,000, 600,000 and 1,000,000 cells $\mathrm{mL}^{-1}$ for sub-clinical and clinical mastitis, positive with a specific mastitis causative pathogen (e.g., Strep. dysgalactiae and E. coli) were studied. Healthy milk (sample H) was used as a negative control as no traces of any photogenic contaminants were obtained through microbiological examination and low SCC score of 71,000 cells $\mathrm{mL}^{-1}$ were acquired, thus expecting minute $\mathrm{Hp}$ concentrations. It

\begin{tabular}{|c|c|c|}
\hline Sample & SCC (cells $\mathrm{mL}^{-1}$ ) & Pathogen \\
\hline $\mathrm{H}$ & 71,000 & N/A \\
\hline CS1 & 353,000 & Strep. dysgalactiae \\
\hline CS2 & 495,000 & Strep. dysgalactiae \\
\hline CS3 & $>1,000,000$ & Strep. dysgalactiae \\
\hline CS4 & 300,000 & E. coli \\
\hline CS5 & 636,000 & E. coli \\
\hline CS6 & $>1,000,000$ & E. coli \\
\hline
\end{tabular}

Healthy milk sample (H), cattle sick milk sample (CS)

should be noted that sample $\mathrm{H}$ was accepted as a representative of other healthy milk samples with similar negative biological contamination and insignificant SCC values $\left(<100,000\right.$ cells $\left.\mathrm{mL}^{-1}\right)$ for this study. Defatted milk samples were reacted with Hb-MNPs according to the noted procedure using optimized conditions. It is expected that upon acute-phase response of cows suffering from mastitis will induce intensified Hp concentrations both in milk and plasma in proportion to the clinical severity of the occurring inflammation. Increased Hp levels will profoundly induce protein-protein ( $\mathrm{Hp}$ $\mathrm{Hb}$ ) complexes formation, thus hindering the peroxidaselike activity of Hb-MNPs within luminol CL system and producing reduced CL intensities. Figure 4a depicts $C L$ signal stability of the bioassay within different milk samples qualities (healthy, sub-clinical or clinical mastitis) in comparison to a milk-free solution (only Hb-MNPs), expecting significant CL values and stability of the latter. 

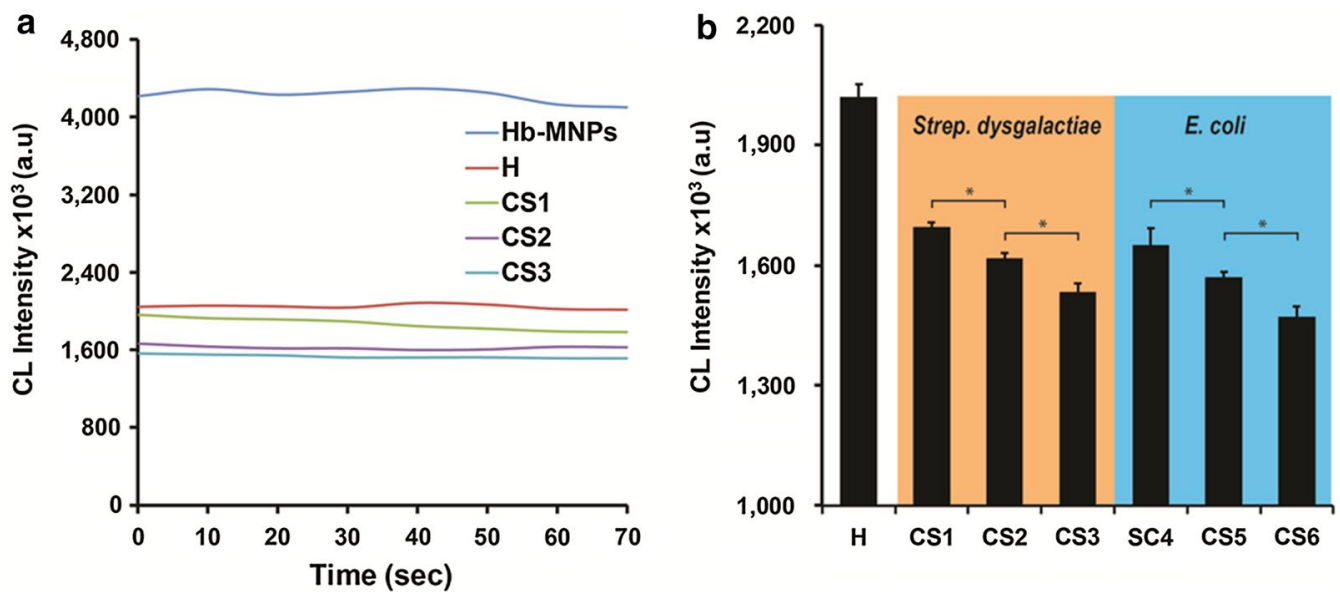

Fig. 4 a CL signal stability of the bioassay within dissimilar milk samples qualities (healthy, sub-clinical or clinical mastitis) and Hb-MNPs (control); b The corresponding CL values within different milk samples for two predominant pathogens (Strep. dysgalactiae and E. coli). Data are reported as mean $\pm S D(n \geq 3)$. *Statistically different (t-test, $p<0.05)$

Indeed, the $C L$ values were reduced upon deterioration of milk quality (escalation in SCC levels), presenting values of $1871 \pm 65 \times 10^{3}, 1626 \pm 22 \times 10^{3}, 1535 \pm 16 \times 10^{3}$ a.u. for CS1, CS2, CS3 (all positive with Strep. dysgalactiae) in comparison to the negative control (sample $\mathrm{H}$ with $\mathrm{CL}$ values of $2052 \pm 24 \times 10^{3}$ a.u.). It should be noted that all examined milk samples presented similar CL signal stability throughout the entire duration of the bioassay in comparison to the stability of Hb-MNPs. Figure $4 \mathrm{~b}$ presents the corresponding $\mathrm{CL}$ values within different milk samples qualities by comparing two predominant pathogens of mastitis (Strep. dysgalactiae and E. coli). Similar CL output was shown for samples CS4, CS5, CS6 (all positive with E. coli pathogen). The resulting further confirm the correlation between the emitted radiation of the presented CL system and the inherent $\mathrm{Hp}$ concentration within milk. Samples CS3 and CS6 depict low $C L$ values of $1534 \pm 22 \times 10^{3}$ and $1458 \pm 38 \times 10^{3}$ a.u., respectively. The inhibited catalytic activity of $\mathrm{Hb}-\mathrm{MNPs}$ within these samples can be attributed to increased biomarker concentrations due to acute clinical state of the examined cows, both positive with pathogenic microbial contamination and elevated SCC scores, above 1000,000 cells $\mathrm{mL}^{-1}$. Overall, these results efficiently differentiate between the different milk qualities based on the proposed liquid phase CL system and offer feasible means for deducing the severity of the occurring bovine mastitis. Moreover, the intensified CL values of highly-loaded catalyst content on the magnetic carrier combined with the option to pre-concentrate the attached target analyte are highly important for on-site detection application, in which less sophisticated or sensitive devices can be used for routine mastitis severity evaluation.

\section{Milk Hp quantification based on CL bioassay}

The CL bioassay was calibrated within the dynamic range of $1 \mathrm{pg} \mathrm{mL}^{-1}$ to $1 \mu \mathrm{g} \mathrm{mL}^{-1} \mathrm{Hp}$, linking the optical output vs the biomarker concentration. Corresponding to the obtained CL data, profound $\mathrm{Hp}$ degree will hinder the catalytic response ascribed to protein-protein $(\mathrm{Hb}-\mathrm{Hp})$ composite association. Figure 5 presents the calibration curve of the CL bioassay for standard Hp concentrations based on Hb-MNPs sensing concept acquired under optimized conditions. Indeed, proportional CL decrease within the entire dynamic range was shown for higher target analyte concentrations, while presenting the fitted regression of the calibration curve $\mathrm{CL}=-155,038$ Ln $\left(\mathrm{C}_{\mathrm{Hp}}\right)+1,620,083\left(R^{2}=0.98\right)$. The limit of detection

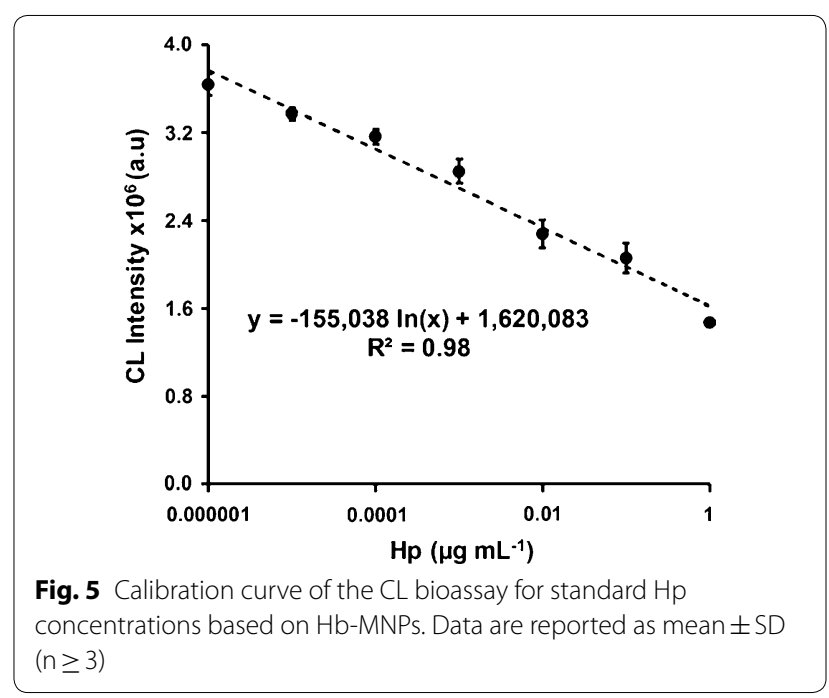


(LOD) of $0.89 \mathrm{pg} \mathrm{mL}^{-1}$ was calculated using the equation of $y_{b}-3 s t d_{b}$, where $y_{b}$ is the averaged CL intensity measured for maximal CL intensity without any $\mathrm{Hp}$ residuals and $3 s t d_{b}$ is the associated standard of deviation, as previously shown [39]. The presented LOD is lower than the many reported optically based research studies (e.g., absorbance, fluorescence, CL, and surface plasmon resonance) utilizing both photon count sensitivity of the CL concept and the pre-concentration of highly loaded catalyst on the magnetic carriers [23, 40-43]. It should be noted that a healthy milk sample (containing insignificant $\mathrm{Hp}$ residues) was added to each Hp reference condition to simulate interferences from milk constituents. Additional file 1: Figure S2 depicts a representative CL stability and averaged data of the healthy milk, which suggests Hp content below the dynamic range of the calibration curve due to elevated emission values. The latter was further verified by calibrating the CL system in buffer conditions presenting similar CL decrease with respect to $\mathrm{Hb}$ catalytic inhibition, see Additional file 1: Figure S3. An alternative means to simulate milk constituents' interferences is by depleting $\mathrm{Hp}$ from the milk by specific interaction with $\mathrm{Hb}$-MNPs followed by magnetic separation and sequentially using the Hp-free milk as a blocking simulant [44]. Next, the regression equation was used for assessing Hp content within the studied samples, see Table 2. The calculated $\mathrm{Hp}$ values support the CL intensities study of the various milk qualities, presenting a similar relationship to the clinical severity of the occurring inflammation. Both pathogens induce similar inflammatory response of increased Hp concentrations at higher SCC values. However, the acute-phase response of E. coli contamination over Strep. dysgalactiae was pronounced by secreting higher $\mathrm{Hp}$ content onto milk while comparing similar SCC values (CS1, CS2, CS3 vs. CS4, CS5, CS6, respectively). The causative pathogen

Table 2 Hp concentrations in milk samples using Hb-MNPs CL emission system in comparison to bovine ELISA

\begin{tabular}{|c|c|c|}
\hline Sample & $\mathrm{Hp} \mathrm{Hb-MNPS}\left(\mu \mathrm{g} \mathrm{mL}^{-1}\right)$ & Hp ELISA $\left(\mu \mathrm{g} \mathrm{mL}^{-1}\right)$ \\
\hline $\mathrm{H}$ & $0.8 \pm 0.2$ & $0.7 \pm 0.1$ \\
\hline $\mathrm{CS}^{\mathrm{a}}$ & $6.1 \pm 0.4$ & $4.7 \pm 0.3$ \\
\hline $\operatorname{CS} 2^{\mathrm{a}}$ & $10.1 \pm 0.9$ & $6.0 \pm 0.4$ \\
\hline $\mathrm{CS}^{\mathrm{a}}$ & $17.6 \pm 2.5$ & $10.6 \pm 0.9$ \\
\hline $\mathrm{CS}_{4}^{\mathrm{b}}$ & $8.4 \pm 2.4$ & $6.0 \pm 0.8$ \\
\hline $\mathrm{CS}^{\mathrm{b}}$ & $13.8 \pm 1.2$ & $9.1 \pm 0.9$ \\
\hline $\mathrm{CS}^{\mathrm{b}}$ & $26.3 \pm 4.3$ & $17.7 \pm 0.4$ \\
\hline
\end{tabular}

Healthy milk sample (H), Cattel sick milk sample (CS)

Data are reported as mean $\pm S D(n \geq 3)$

a Positive with Strep. dysgalactiae pathogen

b Positive with E. coli pathogen origin has been previously demonstrated in several field studies that the animal's immune response is triggered or influenced differently while comparing clinical stage mastitis, favoring E. coli contamination over Strep. dysgalactiae. It should be noted that $E$. coli cause the inflammation around parturition and during early lactation, however trigger severe systemic clinical symptoms at all inflammatory stages [45]. Lastly, the performance of CL bioassay was compared with bovine ELISA technique to verify the validity and compliance of $\mathrm{Hp}$ analysis in real milk samples to the standardize technique used to differentiate milk qualities. Indeed, similar $\mathrm{Hp}$ values trends were obtained for all analyzed samples at various clinical stages of the occurring mastitis, considering the SCC scores and the causative bacteria. The Hp concentrations based on Hb-MNPs overestimate the biomarker content within milk than the equivalent ELISA results, which can be ascribed to the sensitivity differences between the optical techniques. The CL bioassay overpowers the conventional assay by measuring photon count rather than colorimetric absorbance, thus presenting lower LOD values $[10,21,46]$. To further elucidate the calculated $\mathrm{Hp}$ differences, a control experiment with known Hp content $\left(0.005 \mu \mathrm{g} \mathrm{mL}{ }^{-1}\right)$ in buffer and in milk was applied to both sensing techniques (Additional file 1: Figure S2). Additional file 1: Table S4 summarizes the calculated Hp concentrations using $\mathrm{Hb}-\mathrm{MNPs} \mathrm{CL}$ emission based on calibration curve in buffer and in milk conditions and bovine ELISA. Similarly to the performances in real milk samples, the CL bioassay examined in buffer conditions overestimates the spiked $\mathrm{Hp}$ concentration, while the ELISA quantification underestimates its content. The recovery values of both techniques are $120 \%$ and $92 \%$ for CL bioassay and ELISA, respectively, while methods deviation is $130 \%$. The recovery values of the latter condition (milk) are augmented for both techniques and the methods deviation is $133 \%$. The deviation can be attributed to the wide range of reference $\mathrm{Hp}$ concentrations, which are susceptible to heteroscedasticity within semi-logarithmic scale. Moreover, the absolute analyte levels measured by commercial ELISA are known to vary between different manufacturers using similar standard solutions and prone to samples' constituents false interactions [47, 48]. Herein, the concentration trend in complex media are paramount rather the obtained absolute values which are used to determine relative inflammation differences or alternatively to follow the therapy efficiency. Despite the concentration deviation both in milk and in buffer conditions, the presented assay can precisely differentiate dissimilar milk qualities and indicate on animals' clinical stage. The intensified CL signal is advantageous in terms of flexibility and applicability for on-field detection, reducing both the protocol duration and costs per 
assay. The presented assay can be easily adapted for other protein classes inspection upon minor assay modification and improvement. Overall, the developed CL bioassay based on magnetic carriers, which specifically target and pre-concentrate the molecule of interest, is suitable for Hp analysis in milk samples.

\section{Conclusions}

An ultrasensitive $\mathrm{Hp}$ biomarker detection was designed based on the binding capacity of Hb-modified MNPs, while assessing their catalytic activity inhibition within the CL bioassay. Hp concentrations in real milk samples were increased in correlation to the severity of the occurring mastitis and SCC levels. The main advantage of the presented sensing concept is the ability to detect $\mathrm{Hp}$ at clinically relevant concentrations in real milk samples for early bio-diagnostic detection of mastitis, using a simple and cost-effective experimental setup. Moreover, the study demonstrates the possibility to design a simple yet reliable sensing platform to target predictive inflammation biomarkers, which are secreted into plasma or milk at acute-phase response, to differentiate the clinical stage of the animal (sub-clinical, clinical or chronical) and thus adjusting the precise treatment. Furthermore, this proofof-concept can be easily adapted for any human disease associated with Hp (i.e., diabetes, neurological and cardiovascular disorders).

\section{Supplementary information}

Supplementary information accompanies this paper at https://doi. org/10.1186/s12951-019-0569-9.

Additional file 1: Table S1. Peak area comparison of amide bonds vs. Fe-O for the different MNPs modifications obtained by ATR-FTIR. Table S2. MNPs size distribution obtained by DLS. Table S3. Hb binding efficiency to MNPs surface. Table S4. Hp concentrations in spiked buffer and milk samples using $\mathrm{Hb}-\mathrm{MNPs} \mathrm{CL}$ emission system in comparison to bovine ELISA. Figure S1. CL values of the magnetic bioassay for three concentrations of $\mathrm{Hb}$ catalyst $\left(1,10\right.$, and $100 \mu \mathrm{g} \mathrm{mL}^{-1}$ ) within dissimilar milk samples qualities. Figure S2. CL signal stability of the Hb-MNPs bioassay within healthy milk sample and spiked $\mathrm{Hp}$ in buffer and milk. Figure S3. Calibration curve of the CL bioassay for standard $\mathrm{Hp}$ concentrations based on Hb-MNPs in buffer.

\section{Acknowledgements}

Not applicable.

\section{Authors' contributions}

Conception and design: NRN, YH, JPL, GS; Development of methodology: NRN, YH; Manuscript drafting: NRN, YH; Manuscript revision: JPL, GS. All authors read and approved the final manuscript.

\section{Funding}

Not applicable.

\section{Availability of data and materials}

All data generated or analyzed during this study are included in this published article.
Ethics approval and consent to participate

Animal experiments were approved by the Institutional Animal Care Committee of ARO (The Volcani Center), and followed its ethical guidelines (approval number 838/119IL).

\section{Consent for publication}

All authors agreed to submit this study.

\section{Competing interests}

The authors declare that they have no competing interests.

\section{Author details}

${ }^{1}$ Institute of Agricultural Engineering, ARO, The Volcani Center, 50250 Bet Dagan, Israel. ${ }^{2}$ Department of Chemistry, Nanomaterials Research Center, Institute of Nanotechnology \& Advanced Materials (BINA), Bar-llan University, 5290002 Ramat Gan, Israel.

Received: 18 September 2019 Accepted: 31 December 2019 Published online: 07 January 2020

\section{References}

1. Kalmus P, Simojoki H, Pyörälä S, Taponen S, Holopainen J, Orro T. Milk haptoglobin, milk amyloid $\mathrm{A}$, and $\mathrm{N}$-acetyl- $\beta$-D-glucosaminidase activity in bovines with naturally occurring clinical mastitis diagnosed with a quantitative PCR test. J Dairy Sci. 2013;96(6):3662-70.

2. Weng X, Ahmed SR, Neethirajan S. A nanocomposite-based biosensor for bovine haptoglobin on a 3D paper-based analytical device. Sens Actuators B. 2018;265:242-8.

3. Lisowska-Myjak B, Skarżyńska E, Płazińska M, Jakimiuk A. Relationships between meconium concentrations of acute phase proteins. Clin Exp Pharmacol Physiol. 2018:45(11):1218-20.

4. Markanday A. Acute phase reactants in infections: evidence-based review and a guide for clinicians. Open Forum Infect Dis. 2015. https://doi. org/10.1093/ofid/ofv098.

5. Chae J-B, Park J, Jung S-H, Kang J-H, Chae J-S, Choi K-S. Acute phase response in bovine coronavirus positive post-weaned calves with diarrhea. Acta Vet Scand. 2019;61(1):36.

6. Viguier C, Arora S, Gilmartin N, Welbeck K, O'Kennedy R. Mastitis detection: current trends and future perspectives. Trends Biotechnol. 2009;27(8):486-93.

7. Janciauskiene S, Welte T, Mahadeva R. Acute phase proteins: structure and function relationship. Acute phase proteins-regulation and functions of acute phase proteins. London: IntechOpen; 2011.

8. Beer MCD, Ji A, Noffsinger VP, Schridas P, Beer FCD, Tannock LR, et al. Serum amyloid $A 3$ is a high density lipoprotein-associated acute phase protein. Arterioscler Thromb Vasc Biol. 2017;37:A563.

9. Nirala NR, Shtenberg G. Gold nanoparticle size-dependent enhanced chemiluminescence for ultra-sensitive haptoglobin biomarker detection. Biomolecules. 2019;9(8):372.

10. Nirala NR, Pinker N, Desitti C, Shtenberg G. Milk haptoglobin detection based on enhanced chemiluminescence of gold nanoparticles. Talanta. 2019;197:257-63.

11. Ondruschka B, Schuch S, Pohlers D, Franke H, Dreßler J. Acute phase response after fatal traumatic brain injury. J Legal Med. 2018;132(2):531-9.

12. Hiss S, Mielenz M, Bruckmaier R, Sauerwein H. Haptoglobin concentrations in blood and milk after endotoxin challenge and quantification of mammary Hp mRNA expression. J Dairy Sci. 2004;87(11):3778-84.

13. Tiwari A, Dhoble SJ. Recent advances and developments on integrating nanotechnology with chemiluminescence assays. Talanta. 2018;180:1-11.

14. Zhang Y, Zhang R, Yang X, Qi H, Zhang C. Recent advances in electrogenerated chemiluminescence biosensing methods for pharmaceuticals. J Pharm Anal. 2019;9(1):9-19.

15. Shahvar A, Saraji M, Shamsaei D. Smartphone-based chemiluminescence sensing for TLC imaging. Sens Actuators B. 2018;255:891-4.

16. Bui MPN, Brockgreitens J, Abbas A. Gold nanoplate-enhanced chemiluminescence and macromolecular shielding for rapid microbial diagnostics. Adv Healthc Mater. 2018;7(13):1701506-16. 
17. Ahn K-S, Lee JH, Park J-M, Choi HN, Lee W-Y. Luminol chemiluminescence biosensor for glycated hemoglobin (HbA1c) in human blood samples. Biosens Bioelectron. 2016;75:82-7.

18. Islam MS, Kang SH. Chemiluminescence detection of label-free C-reactive protein based on catalytic activity of gold nanoparticles. Talanta. 2011;84(3):752-8.

19. Zhang Z, Guan Y, Xia T, Du J, Li T, Sun Z, et al. Influence of exposed magnetic nanoparticles and their application in chemiluminescence immunoassay. Colloids Surf A. 2017;520:335-42.

20. Li D, Hua M, Fang K, Liang R. BSA directed-synthesis of biocompatible $\mathrm{Fe}_{3} \mathrm{O}_{4}$ nanoparticles for dual-modal T1 and T2 MR imaging in vivo. Anal Methods. 2017;9(21):3099-104.

21. Zhang Q-Y, Chen H, Lin Z, Lin J-M. Comparison of chemiluminescence enzyme immunoassay based on magnetic microparticles with traditional colorimetric ELISA for the detection of serum a-fetoprotein. J Pharm Anal. 2012;2(2):130-5.

22. Jie M, Yu S, Yu F, Liu L, He L, Li Y, et al. An ultrasensitive chemiluminescence immunoassay for fumonisin B1 detection in cereals based on goldcoated magnetic nanoparticles. J Sci Food Agric. 2018;98(9):3384-90.

23. Wang $Y-R$, Yang $Y-H$, Lu C-Y, Chen S-H. Utilization of magnetic nanobeads for analyzing haptoglobin in human plasma as a marker of Alzheimer's disease by capillary electrophoretic immunoassay with laser-induced fluorescence detection. Anal Chim Acta. 2015;865:76-82.

24. Chaichi MJ, Ehsani M. A novel glucose sensor based on immobilization of glucose oxidase on the chitosan-coated $\mathrm{Fe}_{3} \mathrm{O}_{4}$ nanoparticles and the luminol- $\mathrm{H}_{2} \mathrm{O}_{2}$-gold nanoparticle chemiluminescence detection system. Sens Actuators B. 2016:223:713-22.

25. Panwar $\bigvee$, Kumar P, Bansal A, Ray SS, Jain SL. PEGylated magnetic nanoparticles $\left(\mathrm{PEG} @ \mathrm{Fe}_{3} \mathrm{O}_{4}\right.$ ) as cost effective alternative for oxidative cyanation of tertiary amines via CH activation. Appl Catal A. 2015;498:25-31.

26. Hendrickson O, Chertovich J, Zherdev A, Sveshnikov P, Dzantiev B. Ultrasensitive magnetic ELISA of zearalenone with pre-concentration and chemiluminescent detection. Food Control. 2018;84:330-8.

27. Massad-Ivanir N, Shtenberg G, Tzur A, Krepker MA, Segal E. Engineering nanostructured porous $\mathrm{SiO}_{2}$ surfaces for bacteria detection via "direct cell capture". Anal Chem. 2011;83(9):3282-9.

28. Brasford M. A rapid and sensitive method for quantitation of microgram quantities of protein utilizing the principle of protein-dye binding. Anal Biochem. 1976;72:248-54

29. Lellouche J-P, Michaeli S, Liron L, Lellouche E, Kapilov-Buchman Y, inventors; Bar Ilan University, Ramat Gan (IL) assignee. Magnetic inorganic iron-based nanoparticles patent US 2016/0281082 2016 September 29.

30. Shtenberg G, Massad-Ivanir N, Khabibullin A, Zharov I, Segal E. Label-free optical monitoring of proteolytic reaction products using nanoporous silica colloidal assembly. Sens Actuators B. 2018;262:796-800.

31. Gonçalves R, Martins P, Caparrós C, Martins P, Benelmekki M, Botelho G, et al. Nucleation of the electroactive $\beta$-phase, dielectric and magnetic response of poly (vinylidene fluoride) composites with $\mathrm{Fe}_{2} \mathrm{O}_{3}$ nanoparticles. J Non-Cryst Solids. 2013;361:93-9.

32. Rümenapp C, Wagner FE, Gleich B. Monitoring of the aging of magnetic nanoparticles using Mössbauer spectroscopy. J Magn Magn Mater. 2015;380:241-5.

33. Wan J, Cai W, Meng X, Liu E. Monodisperse water-soluble magnetite nanoparticles prepared by polyol process for high-performance magnetic resonance imaging. Chem Commun. 2007:47:5004-6.
34. YoshikiY, lida T, Okubo K, Kanazawa T Chemiluminescence of hemoglobin and identification of related compounds with the hemoglobin chemiluminescence in plasma. Photochem Photobiol. 2001;73(5):545-50.

35. Zhou S-L, Wang J-H, Huang W-H, Lu X, Cheng J-K. Monitoring the reaction of hemoglobin with hydrogen peroxide by capillary electrophoresischemiluminescence detection. J Chromatogr B. 2007;850(1):343-7.

36. Sazhina NN. The inhibitory action of several bioantioxidants and their mixtures in a model hemoglobin-hydrogen peroxide-luminol chemiluminescent system. Biophysics. 2017;62(6):905-13.

37. Wu C-C, Lin H-I, Chang K-W, Mai JD, Shiesh S-C, Lee G-B. Measurement of glycated hemoglobin levels using an integrated microfluidic system. Microfluid Nanofluid. 2015;18(4):613-21.

38. Li Y, Peng W, You X. Determination of dopamine by exploiting the catalytic effect of hemoglobin-stabilized gold nanoclusters on the luminol$\mathrm{NalO}_{4}$ chemiluminescence system. Microchim Acta. 2017;184(9):3539-45.

39. Krismastuti FSH, Pace S, Voelcker NH. Porous silicon resonant microcavity biosensor for matrix metalloproteinase detection. Adv Funct Mater. 2014;24(23):3639-50.

40. Abadieh R, Safi S, Mohsenifar A, Bayat M. Designation of a fluorescencebased nanobiosensor for detection of bovin haptopglobin. Bull Georg Natl Acad Sci. 2015;9:222-8.

41. Åkerstedt M, Björck L, Waller KP, Sternesjö Å. Biosensor assay for determination of haptoglobin in bovine milk. J Dairy Res. 2006;73(3):299-305.

42. Huang G, Ouyang J, Delanghe JR, Baeyens WRG, Dai Z. Chemiluminescent image detection of haptoglobin phenotyping after polyacrylamide gel electrophoresis. Anal Chem. 2004;76(11):2997-3004.

43. Nakagawa H, Yamamoto O, Oikawa S, Higuchi H, Watanabe A, Katoh N Detection of serum haptoglobin by enzyme-linked immunosorbent assay in cows with fatty liver. Res Vet Sci. 1997;62(2):137-41.

44. Vakh C, Pochivalov A, Koronkiewicz S, Kalinowski S, Postnov V, Bulatov A. A chemiluminescence method for screening of fluoroquinolones in milk samples based on a multi-pumping flow system. Food Chem. 2019;270:10-6.

45. Burvenich C, Van Merris V, Mehrzad J, Diez-Fraile A, Duchateau L. Severity of $E$. coli mastitis is mainly determined by cow factors. Vet Res. 2003:34(5):521-64.

46. Chen D, Zhang Y, Xu Y, Shen T, Cheng G, Huang B, et al. Comparison of chemiluminescence immunoassay, enzyme-linked immunosorbent assay and passive agglutination for diagnosis of Mycoplasma pneumoniae infection. Ther Clin Risk Manag. 2018;14:1091.

47. Rød AMK, Harkestad N, Jellestad FK, Murison R. Comparison of commercial ELISA assays for quantification of corticosterone in serum. Sci Rep. 2017;7(1):6748

48. Khan SS, Smith MS, Reda D, Suffredini AF, McCoy JP Jr. Multiplex bead array assays for detection of soluble cytokines: comparisons of sensitivity and quantitative values among kits from multiple manufacturers. Cytom Part B. 2004;61(1):35-9.

\section{Publisher's Note}

Springer Nature remains neutral with regard to jurisdictional claims in published maps and institutional affiliations.

Ready to submit your research? Choose BMC and benefit from

- fast, convenient online submission

- thorough peer review by experienced researchers in your field

- rapid publication on acceptance

- support for research data, including large and complex data types

- gold Open Access which fosters wider collaboration and increased citations

- maximum visibility for your research: over $100 \mathrm{M}$ website views per year

At BMC, research is always in progress.

Learn more biomedcentral.com/submissions 